\title{
Early forest fire detection using low-energy hydrogen sensors
}

\author{
K. Nörthemann ${ }^{1}$, J.-E. Bienge ${ }^{2}$, J. Müller ${ }^{2}$, and W. Moritz ${ }^{1}$ \\ ${ }^{1}$ Humboldt-Universität zu Berlin, Brook-Taylor-Str. 2, 12489 Berlin, Germany \\ ${ }^{2}$ Johann Heinrich von Thünen-Institut, Alfred-Möller-Straße 1, 16225 Eberswalde, Germany \\ Correspondence to: K. Nörthemann (kai.noerthemann@hu-berlin.de)
}

Received: 13 March 2013 - Revised: 4 October 2013 - Accepted: 21 October 2013 - Published: 1 November 2013

\begin{abstract}
Most huge forest fires start in partial combustion. In the beginning of a smouldering fire, emission of hydrogen in low concentration occurs. Therefore, hydrogen can be used to detect forest fires before open flames are visible and high temperatures are generated. We have developed a hydrogen sensor comprising of a metal/solid electrolyte/insulator/semiconductor (MEIS) structure which allows an economical production. Due to the low energy consumption, an autarkic working unit in the forest was established. In this contribution, first experiments are shown demonstrating the possibility to detect forest fires at a very early stage using the hydrogen sensor.
\end{abstract}

\section{Introduction}

Forest fires in today's commercial and cultural landscapes cause large problems and damage. The risk of large forest fires has reduced in the last decades on the basis of technological progress and scientific knowledge. However, great fires appeared in Russia in 2010 and California, United States, in 2009 with massive financial loss and even death (Hirschberger, 2011). In such huge fires the forces of nature are recalcitrant. To avoid this damage a detection of the fire is required when the involved area is still small, and the fire process is still in the early stages. With changing climatic conditions, the potential risk for forest fires will increase in some regions. Since these currently unforeseen events can occur all over the earth, it is necessary to improve a system to warn of the early stages of forest fires.

Present forest fire detection systems are based on the detection of effects, which appear when an open fire already exists. Most of the systems determine heat, open flames or dust particles. Not so common is the detection of gases which occur by smouldering of organic matter before an open fire accrues. The occurrence of hydrogen during smouldering fire was published in the literature (Cofer III et al., 1988; Jackson and Robins, 1994; Grosshandler, 1997; Krause et al., 2006). Amamoto et al. (1990) pointed out that during the burning of wooden building hydrogen levels are raised and that hydrogen is the first detectable event during such an experiment. The concentration of hydrogen created during smouldering is about $20 \mathrm{ppm}$, which was measured in a shielded environment. At the point when the smouldering forest fire should be detected, the expected concentration is even lower. To detect such an occurrence of hydrogen, the sensor must be reliable in measuring such small concentrations. Because of this we use a detector with a very low detection limit; doing so it is possible to measure hydrogen concentration below $5 \mathrm{ppm}$. Hydrogen occurs in the troposphere in a concentration of about $0.4-0.6 \mathrm{ppm}$. The yearly average variate for different locations on the planet and the fluctuation over the year is about $0.1 \mathrm{ppm}$ (Yver et al., 2011). Subsequently, there is no constant hydrogen concentration; however, the change within the natural hydrogen amount is small and will not influence the fire detection using a hydrogen sensor. Carbon dioxide and methane, which are also present in the atmosphere, have no influence on the sensor signal. The changes of other gases like $\mathrm{NO}_{2}\left(0.6-31 \mu \mathrm{g} \mathrm{m}^{-3}\right), \mathrm{SO}_{2}\left(0.2-15 \mu \mathrm{g} \mathrm{m}^{-3}\right), \mathrm{NH}_{3}(0.2-$

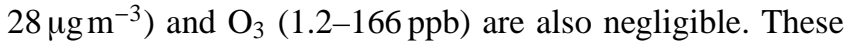
values were measured between 2009 and 2011 at different German forest sites (Fischer, 2013, oral note).

One of the latest comparisons of hydrogen sensors by Boon-Brett et al. (2010) reported the limits of commercial 


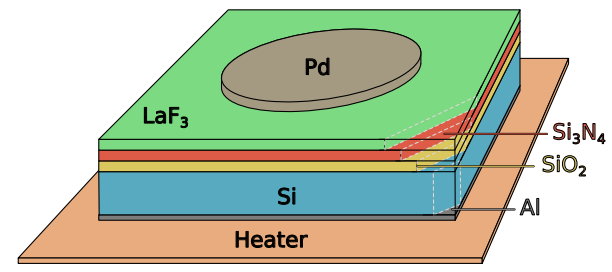

Figure 1. Sketch of the capacitive sensor structure mounted on a heater.

hydrogen sensor detection. None of the reported sensors was able to detect concentration below $10 \mathrm{ppm}$. Because of the low hydrogen concentration induced by smouldering fires, it was necessary to develop a much more sensitive sensor. To gain very sensitive measurements of hydrogen, creating an innovative concept and design of the hydrogen sensor was unavoidable. We developed a low-energy hydrogen sensor set-up for outdoor application. Here we present first results of field experiments in Scots pine stands. Using wood and grass, a smouldering fire was created in the forest. The sensors were placed at different distances from the fire location to monitor the signal which occurs due to a started fire.

\section{Sensor}

The sensor we developed is a metal/solid electrolyte/insulator/semiconductor (MEIS) structure. An explicit sketch is shown in Fig. 1. Silicon oxide and silicon nitride insulators are grown on a silicon wafer. The thickness of this insulator is $150 \mathrm{~nm}$. Afterwards a $150 \mathrm{~nm}$ lanthanum trifluoride layer is grown by physical vapour deposition at high vacuum. The $20 \mathrm{~nm}$ palladium layer is produced by DC sputtering. This layer operates as gate metal. The structure is different to the Lundström sensor (Lundström et al., 1975) because of an additional superionic conductor between the insulator and the gate layer. Due to this additional layer, the dependence of the electrical signal on hydrogen concentration is changed. In contrast to a square root dependency of the Lundström sensor, our sensor shows a logarithmic concentration response. Details about the solid electrolyte layer can be found in Moritz and Krause (2004).

The final sensor structure used in our experiments was $\mathrm{Pd} / \mathrm{LaF}_{3} / \mathrm{Si}_{3} \mathrm{~N}_{4} / \mathrm{SiO}_{2} / \mathrm{Si}$. This sensor chip is a capacitive element, and the capacitance depends on the voltage between gate (palladium) and bulk (silicon, ohmic contact). The capacitance was measured between the backside aluminium contact and the gate. This structure was bonded on top of a ceramic heater which is used for the activation of the sensor. The sensors were activated once a day to improve the response time and the signal. Details and effects of the activation process can be found in Linke et al. (2012). During operation the sensor does not need to be heated. The measurements were done at ambient temperature. Due to this

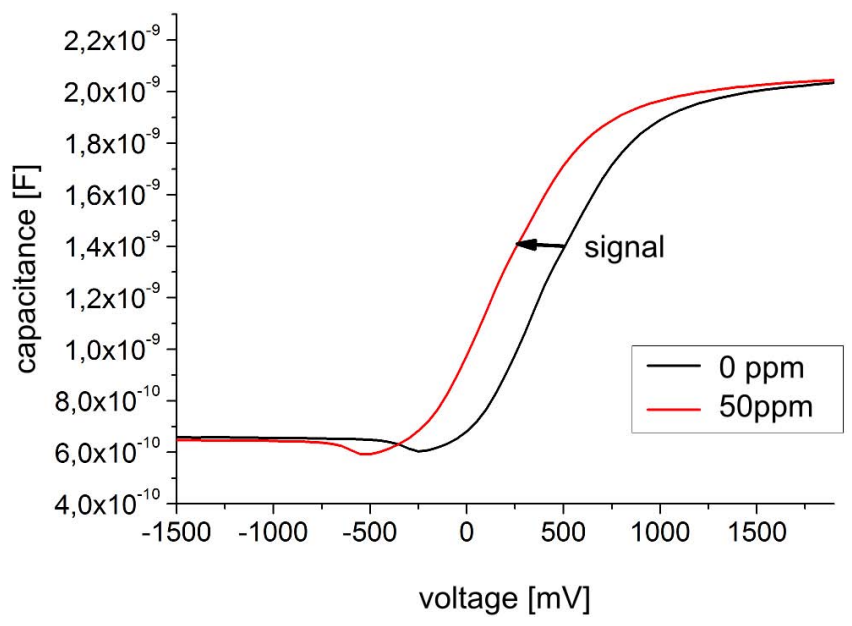

Figure 2. Changes in the capacitance voltage plot due to hydrogen uptake. When hydrogen occurs at the palladium surface, the graph is shifted to lower potential.

fact, the power consumption of the electronics is low, and operation with batteries is possible.

When hydrogen reacts with the sensor structure, the capacitance/voltage behaviour changes, which is shown in Fig. 2. Hydrogen molecules dissociate at the palladium surface. And hydrogen atoms are solved in the palladium and interact with the lanthanum trifluoride layer. Via this process, additional charges occur, and the chemical potential is modified. The result is a shift of the capacitance voltage plot to lower potential in comparison to absence of hydrogen. To determine the hydrogen concentration, only the voltage shift has to be measured. The voltage shift of this sensor shows a logarithmic dependency to the hydrogen concentration (Moritz et al., 2006). Due to this relation, it is possible to measure hydrogen in a very large concentration range. Concentrations as high as $10 \%(100000 \mathrm{ppm})$ and very low concentrations $(<5 \mathrm{ppm})$ can be measured. To detect tiny amounts of the tracing gas, this is necessary for an alarm system in forests where dilution is a major effect. Details of the response to hydrogen with these sensor systems were described by Moritz et al. (2006).

\section{Experiments}

For the field experiment an electronic design was developed which measures the capacitance of the sensor and adjusts the applied potential in feedback mode. These electronics measure all data autonomously and are able to store the collected data. With a commercial XBee RF (radio frequency) module, a wireless communication was implemented so that it was able to control all sensors and collect all data via a computer. Because of this wireless communication, it is practicable to arrange the sensors at different positions in a large area in the 


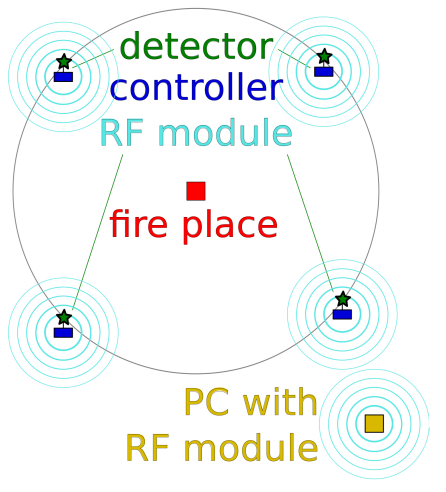

Figure 3. Experimental set-up in the forest. The sensors were placed around the fire place at different trees. The experiments were done with changing height and distance of the sensors. The communication with the sensors was done with an RF module.

forest. The experimental environment was established inside of a mixed forest stand. For safety reasons the smouldering fire was started in a metal bowl. For this first proof of concept, small fires including an area below $3 \mathrm{~m}^{2}$ were burned. Around the fire place, the sensors were mounted at different trees. Details of the experimental set-up are illustrated in Fig. 3. For the different experiments, the heights of the sensors varied between 1 and $4 \mathrm{~m}$. Also the distances between fire and sensors were changed in different measurements.

Figure 4 shows the sensor signal for different hydrogen concentrations. This graph illustrates the logarithmic dependency between the hydrogen concentration and the resulting sensor signal from below 1 to $1000 \mathrm{ppm}$. Due to this logarithmic relation, it is possible to measure very low hydrogen concentration with our sensor. With this signal-concentration relation, even tiny hydrogen occurrence results in a detectable signal response. So our sensor is able to trace tiny quantities of hydrogen with concentrations below $5 \mathrm{ppm}$, which is beneath the detection limits that Boon-Brett et al. (2010) reported in an overview of commercial hydrogen sensors. Thus a small lower detection limit is necessary for this application because hydrogen only occurs in slight concentrations during a smouldering fire and is additionally diluted in the forest. The detection of concentration up to $10 \mathrm{vol} . \%$ and the sensor stability are published elsewhere (Moritz et al., 2006; Lang et al., 2013).

\section{Results}

To investigate the thinning of the hydrogen in a smouldering fire, an experiment was carried out in a hall with a size of about $25 \mathrm{~m} \times 12 \mathrm{~m} \times 7 \mathrm{~m}$. Nine small beech bricks were heated with a heating plate until fumes were formed. This set-up is related to the test fire TF2 described in DIN EN 54 (DIN, 2000). But all experimental details of the norm were not fulfilled. Only a set-up was used in which surely hydrogen is formed in a smouldering fire. At a distance of $3.5 \mathrm{~m}$

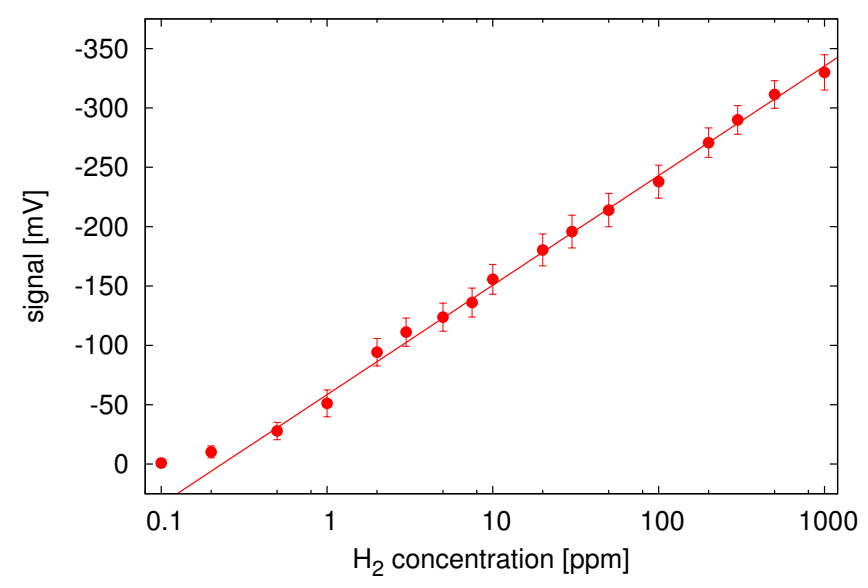

Figure 4. Sensor signal as function of the hydrogen concentration in the range from 0.1 to $1000 \mathrm{ppm}$. Shown is the signal average over 16 different sensors with standard deviation. The sensor has a logarithmic dependency between the hydrogen concentration and sensor signal. This relation allows the measurement of very low hydrogen concentrations.

from the fire place, sensors were mounted at different heights in this closed room. For details of the set-up, see Fig. 5a. The data of this test fire are shown in Fig. 5b. In all three sensors, signal differences due to the occurrence of the fire are detectable. The signal levels in this experiment of about $200 \mathrm{mV}$ are in a range where no complicated signal processing is necessary. On the measured signal in Fig. 5b, some fluctuations are visible. Such fluctuations were also visible in the smoke of the smouldering fire. The first change is visible about $3 \mathrm{~min}$ after the heating plate was switched on. This time includes the heating of the heating plate, with a resistance heater and the following heating of the beech bricks. The response time strongly depends on the parameter of the heating plate and is not discussed here in detail. With this experiment we only prove that with the selected hydrogen sensor it is possible to detect a smouldering fire.

Forests with open canopies do not have limits or boundaries, resulting in hydrogen being diluted and widely spread in the air around. The treetop is only a tiny limit and will not prevent the rise of the hydrogen. Due to this, the size of the fire was increased to up to $2 \mathrm{~m}^{2}$. With this the amount of hydrogen is increased, and the thinning starts at a higher concentration. Due to the fact that the fire was started with grass and moistened wood, also a lot of smoke was created. By watching this visible fire, an estimation can be predicted where the hydrogen should appear.

In a field experiment the wind direction has an influence, being inhomogeneous inside a forest. Major influence factors on the wind directions are stand structure, stand density, tree height and age. Trees produce major turbulence inside the forest. Figure 6 shows the different wind profiles of two positions inside the stand. Even if those measurement spots had only a distance of $200 \mathrm{~m}$, both plots would still be 
(a)

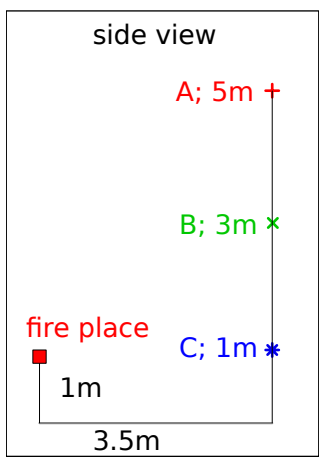

(b)

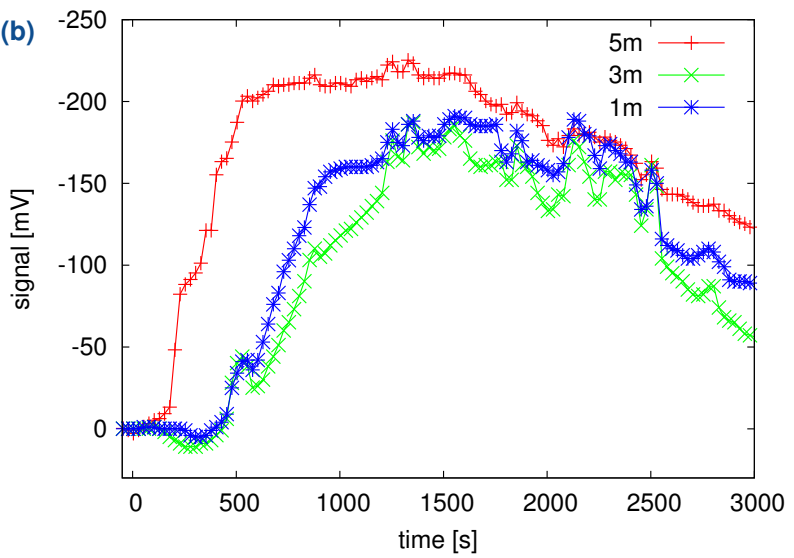

Figure 5. Indoor experiment in a hall with a size of $25 \times 12 \times 7 \mathrm{~m}^{3}$. On a heating plate, wood was heated according to EN54; at three different positions hydrogen sensors were mounted, as illustrated in (a). The measured signals are shown in (b). All sensors detect a change due to the smouldering fire.

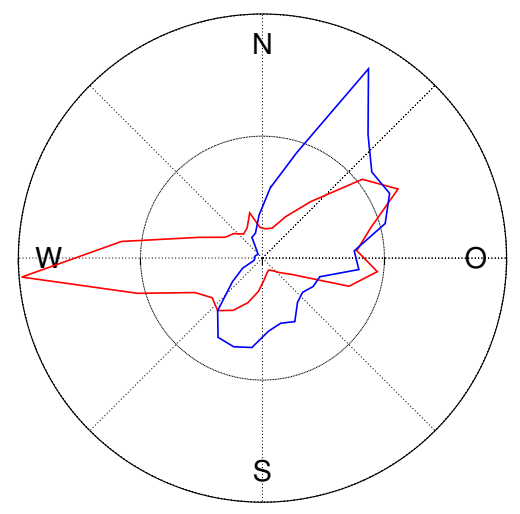

Figure 6. Frequency of the wind direction in the forest at two different positions. Both data sets were collected over one year. The measurement points had a lateral distance of $200 \mathrm{~m}$. The difference is caused by the unequal structure of both standings (red: open structure; blue: closed structure).

completely different. Because of this it is not possible to get a uniform wind direction over the complete measurement area. The wind is also dependent on time. Due to this complexity, there are no indicators of the wind direction in the following plots.

The initial forest experiment was done on a small scale. A smouldering fire of approximately $0.5 \mathrm{~m}^{2}$ was burned at a height of $50 \mathrm{~cm}$ above the ground. Eight sensors were positioned at a height of $1 \mathrm{~m}$ and $3 \mathrm{~m}$ in four different directions. The lateral distance between fire and sensors was $5 \mathrm{~m}$. The arrangement is shown in Fig. 7a. In Fig. 7b the corresponding sensor signals are displayed. Six sensors show a signal due to the smouldering fire. The absence of a reaction at the sensors $\mathrm{C}$ and $\mathrm{E}$ is caused by the wind direction. It is evident that the height of the sensor has an influence on the signal. Due to the wind and crown at this experiment, the major effect was measured at a height of $1 \mathrm{~m}$.
When the distance between sensor and fire place was enhanced, the sensors were mounted higher than $1 \mathrm{~m}$, because the visible smoke of the fire was approximately at a height of $3 \mathrm{~m}$ and above. Mounting the sensor higher than $5 \mathrm{~m}$ was much more complicated, and inside of the treetop the RF communication would be inhibited.

An expanded experiment was done with the same fire size but a larger distance of the sensors to the fire. The sensors were placed in a circle with a radius of about $25 \mathrm{~m}$, and the fire was located in the centre. The sensors were mounted to different trees at a height of about 3 to $4 \mathrm{~m}$. The set-up is shown in Fig. 8. In this figure the sensor signals are also displayed. In the data of sensors $\mathrm{B}, \mathrm{C}$ and $\mathrm{H}$, a clear signal difference is visible. This change is caused by the hydrogen which occurs during the smouldering fire. This shows that the fire was detected by these three sensors. The difference of about $24 \mathrm{mV}$ is slightly above the detection limit. This small signal is caused by the small fire of about $0.5 \mathrm{~m}^{2}$. In this plot also a background fluctuation of about $4 \mathrm{mV}$ is visible. This signal variation does not exist in the laboratory environment, when the sensors are measured in a known constant hydrogen concentration. In such a set-up the noise is below $0.2 \mathrm{mV}$. The reason could be variations of the hydrogen concentration in the forest; however, the shielding of the sensor can also cause this effect. In this first experiment the sensors were only covert by a metal plate to prevent direct light incidence. Reflections were only minimised by painting the housing and plate with black paint. The optimisation of the sensor shielding is now in progress to reduce the outside effects, and to be sure that only hydrogen can pass to the sensor and reduce the influence factors.

To prove the usability of the sensor in a realistic environment, enhanced distances were also measured. In Fig. 9a the set-up is described where the distance between fire and sensor was approximately $110 \mathrm{~m}$. To measure hydrogen in this huge dilution due to the enormous volume, the size of the 
(a)

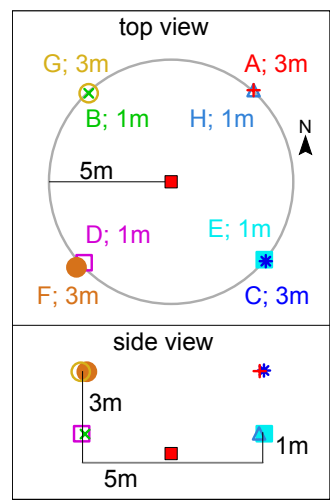

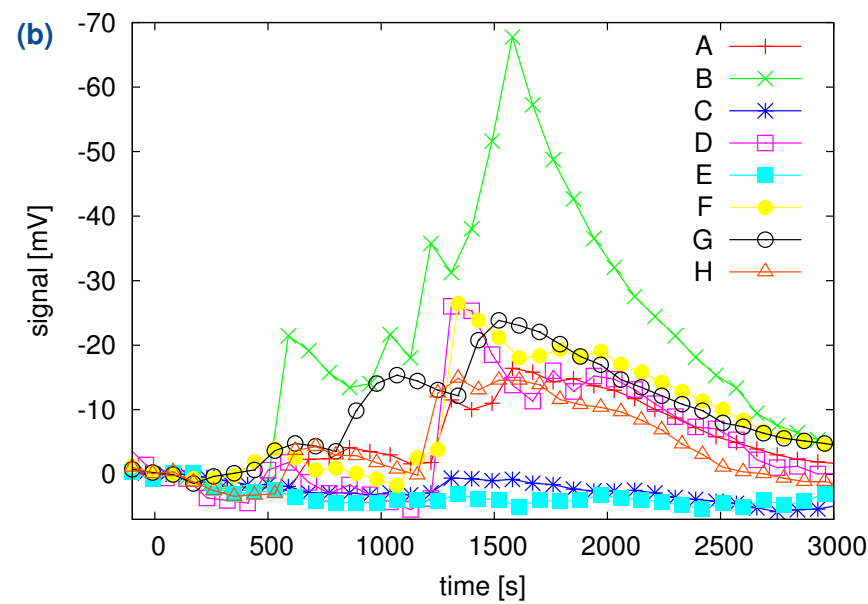

Figure 7. Experiment in the forest with distance between fire and sensors of $5 \mathrm{~m}$. The sensors were placed in four directions at a height of $1 \mathrm{~m}$ and $3 \mathrm{~m}$ as illustrated in part (a). In part (b) the corresponding sensor signals are plotted. The dependency of the wind direction is visible. Also the influence of the detector height can be observed. In this configuration the main signal was observed at a height of $1 \mathrm{~m}$.

(a)

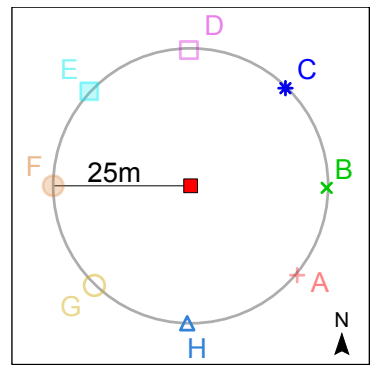

(b)

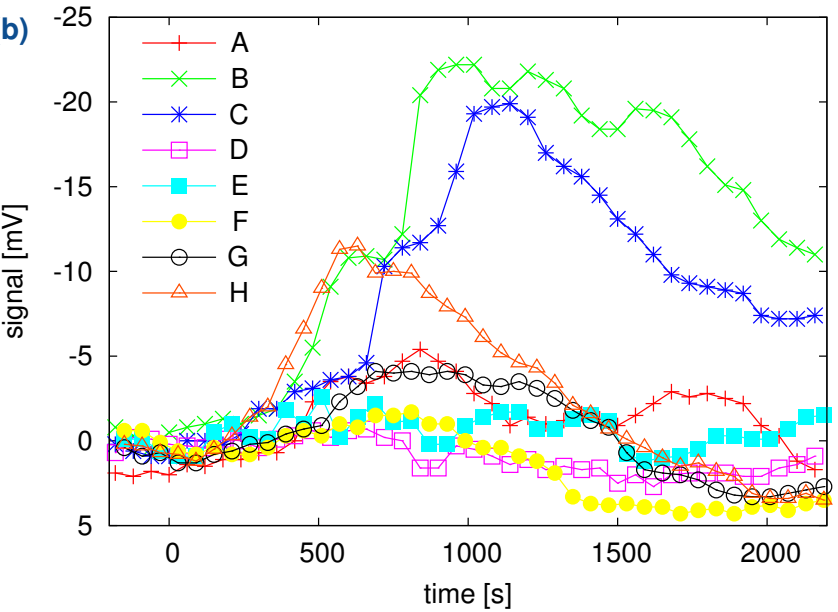

Figure 8. Experiment in the forest with a distance between fire and sensors of $25 \mathrm{~m}$. The sensors were mounted at a height of 3 to $4 \mathrm{~m}$. The position of the sensors is shown in part (a). The measured sensor signal is displayed in part (b). This graph illustrates very clearly a signal difference due to the fire at the sensors $\mathrm{B}, \mathrm{C}$ and $\mathrm{H}$.

fire was increased to about $2 \mathrm{~m}^{2}$, which is still small at the scale of forest fires. The corresponding signal is displayed in Fig. 9b. In this experiment the sensors B, C and F show a significant change in the signal. For these sensors the distance to the fire was 25 and $105 \mathrm{~m}$. Even at sensor $\mathrm{H}$, with a distance of about $115 \mathrm{~m}$, a small influence of the fire appeared.

\section{Discussion and outlook}

The measurements in the forest (see Figs. 7, 8 and 9) reveal that not all placed sensors show a signal difference after the fire was started. This is caused by the fact that the hydrogen is transported by the wind from the fire to the sensor. The wind direction therefore has an important influence where this propagation occurs. In Fig. 7 the sensors $\mathrm{C}$ and $\mathrm{E}$ show no relevant change after the fire was started. This is caused due to the fact that the wind was blowing away from where the sensors were located to the fire place. All other sensors in this set-up detect the hydrogen from the small fire. It is because the distance of $5 \mathrm{~m}$ to the fire is still small. This short distance and open environment has also the effect that the most highly placed sensors do not show a major signal difference. The wind has a primary influence on the measured signal. The time between starting time of the smouldering fire and the first occurrence of a signal change was from $5 \mathrm{~min}$ to $30 \mathrm{~min}$. When this response time is measured, the convection time in the forest has to be accounted for. With this experiment the occurrence of visible smoke at the sensor and measured hydrogen signal were the same. To equate the occurrence of hydrogen with the existence of smoke is only a 
(a)

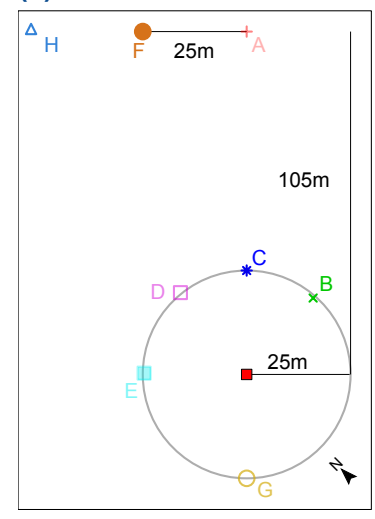

(b)

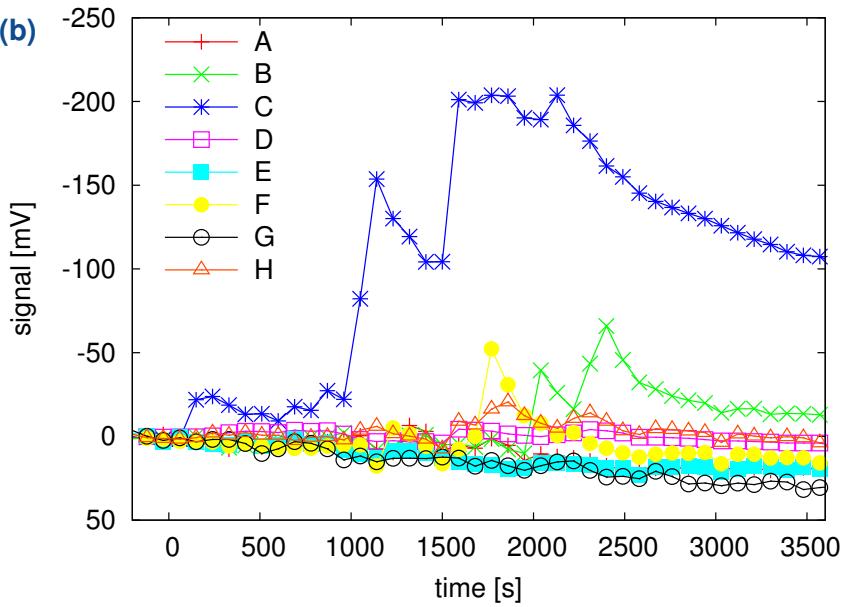

Figure 9. Experiment in the forest with a sensor distance between 25 and $115 \mathrm{~m}$. In part (a) the experimental set-up is pictured. The sensor signals are displayed in part (b). Three sensors show a significant difference due to the fire $(\mathrm{C}, \mathrm{B}$ and $\mathrm{F})$. In the signal of sensor $\mathrm{H}$, a small change is visible.

rough guess. But it illustrates the possibility in which speed fire products can be detected.

A distance of $110 \mathrm{~m}$ between fire place and sensor (Fig. 9) is a large expanse; the signals of sensor F still show significant fluctuations which are also visible at other, more closely situated sensors. This shows that monitoring of forest fires with the presented sensors is possible. For the coverage of huge forest areas, the distance has to be increased where a fire is still detectable. A rough estimation with a sensor to sensor distance of $100 \mathrm{~m}$ gives a density of 1 sensor per ha. In this case 1 million sensors are needed to cover all the forests in the German federal state of Brandenburg. To reduce the number of necessary sensors, the distance between the sensors has to be increased. Further experiments are planned where distances between fire and sensors are increased. When the sensors are used outside of a controlled sand box, an advanced data analysis has to be developed to correlate the signals of different sensors. An autonomous process has to be found which decides independently to trigger a fire alarm. The measurements have shown that with increasing wind speed it becomes easier to detect hydrogen at distant positions. High wind speed is one of the factors favouring forest fires.

In this publication the sensors use a ceramic heater with a size of $7 \times 7 \mathrm{~mm}^{2}$. This geometry is not the optimal set-up. One of the topics which we are now working on is to deposit a heater directly around the palladium dot displayed in Fig. 1. Due to this the energy which is consumed during heating can be reduced by a factor more than 1000 . Another part which can be optimised is the RF communication. For this first experiment we included an RF module where it is sure that the communication will work. Further investigation can reduce the additional energy consumption. By doing all these opti- misations, the battery lifetime can be enhanced from weeks to several years.

\section{Summary}

In these first experiments we have shown that hydrogen is formed during smouldering fire, and this hydrogen is detectable outside in the forest with the newly developed sensors. The shielding of the detectors has to be optimised to avoid side effects which also change the signal. The response time was below $5 \mathrm{~min}$ from the time the fire was started. This time includes the convection of the hydrogen from the fire to the sensor over a distance up to $25 \mathrm{~m}$. A significant change in the signal due to a fire was measured at a distance of about $110 \mathrm{~m}$.

Acknowledgements. The authors would like to thank Michael Dallmer, Michael Milstrey and Michael Rothe for their support during the measurements. This work was financially supported by Zentrales Innovationsprogramm Mittelstand (ZIM) in the project InPriWa.

Edited by: M. Penza

Reviewed by: two anonymous referees

\section{References}

Amamoto, T., Tanaka, K., Takahata, K., Matsuura, S., and Seiyama, T.: A fire detection experiment in a wooden house by $\mathrm{SnO}_{2}$ semiconductor gas sensors, Sensor. Actuat. B-Chem., 1, 226-230, doi:10.1016/0925-4005(90)80206-F, 1990.

Boon-Brett, L., Bousek, J., Black, G., Moretto, P., Castello, P., Hübert, T., and Banach, U.: Identifying performance gaps in hydrogen safety sensor technology for automotive and 
stationary applications, Int. J. Hydrogen Energ., 35, 373-384, doi:10.1016/j.ijhydene.2009.10.064, 2010.

Cofer III, W. R., Levine, J. S., Riggan, P. J., Sebacher, D. I., Winstead, E. L., Shaw Jr., E. F., Brass, J. A., and Ambrosia, V. G.: Trace Gas Emissions From a Mid-Latitude Prescribed Chaparral Fire, J. Geophys. Res., 93, 1653-1658, doi:10.1029/JD093iD02p01653, 1988.

DIN: EN 54-7, 2000.

Fischer, U.: Database of the Programme Co-ordinating Centre (PCC) of ICP Forests, 2013.

Grosshandler, W.: Towards the development of a universal fire emulator-detector evaluator, Fire Safety J., 29, 113-127, doi:10.1016/S0379-7112(96)00031-8, 1997.

Hirschberger, P.: Wälder in Flammen, http:/www.wwf.de/ fileadmin/fm-wwf/Publikationen-PDF/110727_WWF_ Waldbrandstudie.pdf, 2011.

Jackson, M. and Robins, I.: Gas sensing for fire detection: Measurements of $\mathrm{CO}, \mathrm{CO}_{2}, \mathrm{H}_{2}, \mathrm{O}_{2}$, and smoke density in European standard fire tests, Fire Safety J., 22, 181-205, doi:10.1016/03797112(94)90072-8, 1994.

Krause, U., Schmidt, M., and Lohrer, C.: A numerical model to simulate smouldering fires in bulk materials and dust deposits, J. Loss Prevent. Proc., 19, 218-226, doi:10.1016/j.jlp.2005.03.005, 2006.

Lang, M., Banach, U., Nörthemann, K., Gerlitzke, A.-K., Milstrey, M., Kaufer, R., Woratz, M., Hübert, T., and Moritz, W.: Longterm stability of a MEIS low energy hydrogen sensor, Sensor. Actuat. B-Chem., 187, 395-400, doi:10.1016/j.snb.2012.12.081, 2013.
Linke, S., Dallmer, M., Werner, R., and Moritz, W.: Low energy hydrogen sensor, Int. J. Hydrogen Energ., 37, 17523-17528, doi:10.1016/j.ijhydene.2012.07.072, 2012.

Lundström, K. I., Shivaraman, M. S., and Svensson, C. M.: A hydrogen-sensitive Pd-gate MOS transistor, J. Appl. Phys., 49, 3876, doi:10.1063/1.322185, 1975.

Moritz, W. and Krause, S.: Solid state chemical sensors using $\mathrm{LaF}_{3}$ thin layer structures, Recent Res. Devel. Solid State Ionics, 2, 243-279, 2004.

Moritz, W., Fillipov, V., Vasiliev, A., Cherkashinin, G., and Szeponik, J.: A Field Effect Based Hydrogen Sensor for Low and High Concentrations, ECS Transactions, 3, 223-230, doi:10.1149/1.2357262, 2006.

Yver, C. E., Pison, I. C., Fortems-Cheiney, A., Schmidt, M., Chevallier, F., Ramonet, M., Jordan, A., Søvde, O. A., Engel, A., Fisher, R. E., Lowry, D., Nisbet, E. G., Levin, I., Hammer, S., Necki, J., Bartyzel, J., Reimann, S., Vollmer, M. K., Steinbacher, M., Aalto, T., Maione, M., Arduini, J., O’Doherty, S., Grant, A., Sturges, W. T., Forster, G. L., Lunder, C. R., Privalov, V., Paramonova, N., Werner, A., and Bousquet, P.: A new estimation of the recent tropospheric molecular hydrogen budget using atmospheric observations and variational inversion, Atmos. Chem. Phys., 11, 3375-3392, doi:10.5194/acp-11-3375-2011, 2011. 